\title{
Wavenumber-4 spectral component extracted from TIMED/SABER observations
}

\author{
Xing $\mathrm{Li}^{1,2,3,4^{*}}$, WeiXing Wan ${ }^{1,4,5,6}$, JinBin Cao ${ }^{2,3}$, and ZhiPeng Ren ${ }^{1,4,5,6}$ \\ ${ }^{1}$ Key Laboratory of Earth and Planetary Physics, Institute of Geology and Geophysics, Chinese Academy of Sciences, Beijing 100029, China; \\ ${ }^{2}$ School of Space and Environment, Beihang University, Beijing 100083, China; \\ ${ }^{3}$ Key Laboratory of Space Environment Monitoring and Information Processing, Ministry of Industry and Information Technology, Beijing 100083, China; \\ ${ }^{4}$ Beijing National Observatory of Space Environment, Institute of Geology and Geophysics, Chinese Academy of Sciences, Beijing 100029, China; \\ 5 Innovation Academy for Earth Science, Chinese Academy of Sciences, Beijing 100029, China; \\ ${ }^{6}$ University of the Chinese Academy of Sciences, Beijing 100049, China
}

Key Points:

- Vertical profiles and global structures of the wavenumber spectrum are presented

- Short period variation of the wave number 4 component is analysed

- A new approach is proposed to discuss the wave number 4 component

Citation: Li, X., Wan, W. X., Cao, J. B., and Ren, Z. P. (2020). Wavenumber-4 spectral component extracted from TIMED/SABER observations. Earth Planet. Phys., 4(5), 436-448. http://doi.org/10.26464/epp2020040

\begin{abstract}
The wavenumber spectral components $W N_{4}$ at the mesosphere and low thermosphere (MLT) altitudes (70-10 km) and in the latitude range between $\pm 45^{\circ}$ are obtained from temperature data $(T$ ) observed by the Sounding of the Atmosphere using Broadband Emission Radiometry (SABER) instruments on board the National Aeronautics and Space Administration (NASA)'s Thermosphere-lonosphere-Mesosphere Energetics and Dynamics (TIMED) spacecraft during the 11-year solar period from 2002 to 2012. We analyze in detail these spectral components $W N_{k}$ and obtain the main properties of their vertical profiles and global structures. We report that all of the wavenumber spectral components $W N_{k}$ occur mainly around $100 \mathrm{~km}$ altitude, and that the most prominent component is the wavenumber spectral component $W N_{4}$ structure. Comparing these long duration temperature data with results of previous investigations, we have found that the yearly variation of spectral component $W N_{4}$ is similar to that of the eastward propagating non-migrating diurnal tide with zonal wavenumber 3 (DE3) at the low latitudes, and to that of the semi-diurnal tide with zonal wavenumber 2 (SE2) at the mid-latitudes: the amplitudes of the $A_{4}$ are larger during boreal summer and autumn at the low-latitudes; at the mid-latitudes the amplitudes have a weak peak in March. In addition, the amplitudes of component $W N_{4}$ undergo a remarkable short period variation: significant day-to-day variation of the spectral amplitudes $A_{4}$ occurs primarily in July and September at the low-latitudes. In summary, we conclude that the non-migrating tides DE3 and SE2 are likely to be the origins, at the low-latitudes and the mid-latitudes in the MLT region, respectively, of the observed wavenumber spectral component $W N_{4}$.
\end{abstract}

Keywords: TIMED observations; wavenumber spectral components; non-migrating tides; short period variation

\section{Introduction}

The mesosphere and low thermosphere (MLT) is an important region coupling the lower and upper parts of the atmosphere. Produced by the gravitational forces of the moon and sun, as well as the thermal action of the sun, the whole atmosphere presents a host of large-scale oscillations (Chapman and Lindzen, 1970). Active atmospheric oscillations in the MLT region, including gravity waves, atmospheric thermal tides, and planetary-scale internal waves, propagate through this region, leading to energy and momentum transportations from lower to higher altitudes.

Correspondence to: X. Li, lixing@buaa.edu.cn

Received 11 MAR 2020; Accepted 23 APR 2020.

Accepted article online 02 JUL 2020.

(C) 2020 by Earth and Planetary Physics.
Recently, lots of space instruments have been used to investigate the atmospheric oscillations at the MLT altitudes. For example, a global measurement of atmospheric tides was obtained by using temperature observations from the Limb Infrared Monitor of the Stratosphere (LIMS) instrument on the Nimbus 7 satellite (Hitchman and Leovy, 1985; Forbes and Wu D, 2006). The Sounding of the Atmosphere using Broadband Emission Radiometry (SABER) instrument on board NASA's Thermosphere-lonosphere-Mesosphere Energetics and Dynamics (TIMED) satellite has provided the global structure and climatological (annual and inter-annual variation) characteristics of the large-scale waves and atmospheric temperature tides (e.g., Garcia et al., 2005; Zhang XL et al., 2006; Mukhtarov et al., 2009; Xu JY et al., 2009; Pancheva et al., 2010; John and Kumar, 2011; Gu SY et al., 2013). Previous descriptions of atmospheric tides have been based also on wind measurements 
from the High Resolution Doppler Imager (HRDI) on board the Upper Atmosphere Research Satellite (UARS) (e.g., Burrage et al., 1995; Khattatov et al., 1997; Huang FT and Reber, 2003). Moreover, global distributions of diurnal and semi-diurnal tides were observed from the Microwave Limb Sounder (MLS) on the UARS (Manson et al., 2002). The wind Imaging Interferometer (WINDII) on the UARS also observed thermospheric wind tidal signatures and equatorial wavenumber 4 density perturbations (McLandress et al., 1994, 1996). In addition, TIMED Doppler Interferometer (TIDI) measurements were analyzed for diurnal non-migrating wind tides (e.g., Oberheide et al., 2006; Wu Q et al., 2008; Xu JY et al., 2009).

It was Sagawa et al. (2005) and Immel et al. (2006) who first reported the prominent $W_{4}$ component in the IMAGE/FUV observation. Lin CH et al. (2007) analyzed electron density from GPS radio occultation measurements of FORMOSAT-3/COSMIC and found that four electron density peaks exist above $250 \mathrm{~km}$. In addition, Wan W et al. (2008) studied the seasonal variation of the $W N_{4}$ component in the total electron content (TEC). Previous researchers have suggested that the prominent longitudinal wavenumber component $W N_{4}$ could be present in almost all the physical parameters of the ionosphere and of the thermosphere, including the F-region airglow (England et al., 2006), $E \times B$ drifts (e.g., Hartman and Heelis, 2007; Kil et al., 2007; Ren ZP et al., 2009), upper thermospheric winds (Häusler and Lühr, 2009), the ion density (Kil et al., 2007), electron density, and the thermospheric zonal wind (Lühr et al., 2007), to name just a few. Furthermore, Oberheide et al. (2011) identified a dominant wavenumber component $W N_{4}$ in the longitude profile of the zonal wind in the MLT region. These authors related the wave pattern $W N_{4}$ to the eastward-propagating non-migrating diurnal tide with zonal wavenumber 3 (DE3) and the eastward-propagating non-migrating semidiurnal tide with zonal wavenumber 2 (SE2). DE3 and SE2 are produced in the troposphere by the release of latent heat (Hagan and Forbes, 2002,2003 ) and exhibit four wave peaks when seen from a SunSynchronous view.

Recently, using data from the HRDI and WINDII instruments on the UARS, Wu Q et al. (2008) and Huang FT and Reber, (2004) found that the zonal wind of DE3 is stronger and occurs primarily between the June solstice and September equinox near the equator, while the meridional wind spectral component is relatively weaker and occurs during the March and September equinoxes. Similar results have been obtained from analysis of data from the TIDI and SABER instruments on board the TIMED satellite (e.g., Oberheide et al., 2006; Chen ZY and Lü DR, 2007; Oberheide and Forbes, 2008). In addition, Bruinsma and Forbes (2010), England et al. (2010), Oberheide et al. (2011) and Miyoshi et al. (2012) demonstrated the importance of the SE2 for generation of the wave-4 structure at the mid-latitudes. Thus, we suggest that the observed annual variation of the spectral component $W N_{4}$ in atmospheric parameters should correspond to that of DE3 and SE2 tides.

Several studies over the last couple of decades have shown that a noticeable longitudinal wavenumber spectrum would be present in the MLT region. Hence, we report results of preliminary studies of the wavenumber spectrum in atmospheric parameter $(T)$ at the
MLT altitudes observed by the SABER instruments on board NASA's TIMED spacecraft, which was launched on 7 December 2001. Due to the slow precession of this satellite's orbit, almost complete local time coverage is achieved every 60 days. During the last decade, investigators have studied the climatological (annual and inter-annual variation) characteristics of atmospheric tides and planetary waves by accumulating daily SABER temperature data in a running window of 2 months (60 days) length. In this report, we suggest that SABER data can reveal meteorological (short period variation) characteristics of the large-scale waves in the MLT region, from a new point of view. We use the global observations of atmospheric parameter ( $T$ ) from TIMED/SABER to study the longitudinal wavenumber spectrums over the mid-low latitudes in the MLT region. Further, we obtain wavenumber spectrums, filtered from the extracted long-period atmospheric parameters, and investigate their vertical profiles and climatological and meteorological characteristic. Our results support the suggestion that the longitudinal wavenumber spectral components may have their origin in the non-migrating tides.

The main purpose of the present work is to investigate the longitudinal wavenumber spectral component $W N_{4}$ of the atmospheric parameter $(T)$ in the MLT region, picked up from the TIMED/SABER observation data sets. Section 2 describes the TIMED/SABER observation data and the analysis methods. In Section 3 we present the analysis of the main wavenumber spectral components $W N_{k}$ and analyze in detail the short period variation of the longitudinal wavenumber spectrum $W N_{4}$. In Section 4 we compare the short period variation of the main spectrum $W N_{4}$ with data regarding the non-migrating tides. The last section presents our summary and conclusions.

\section{Data Set and Analysis Method}

In this paper, we will analyze variations of the wavenumber spectral components $W N_{k}$ and study in detail the day-to-day variation of the wavenumber- 4 spectral component using temperature observations from the SABER instrument on board NASA's TIMED satellite.

\subsection{TIMED Observations}

Since late January 2002, the SABER (Sounding of the Atmosphere using Broadband Emission Radiometry) instrument on the Thermosphere lonosphere Mesosphere Energetics and Dynamics (TIMED) satellite has provided global temperature $(T)$ observations for the latitudes range $50^{\circ} \mathrm{N}-50^{\circ} \mathrm{S}$ from the lower stratosphere to the lower thermosphere $(20-120 \mathrm{~km})$. These data provide an unprecedented opportunity for studying in detail the climatological characteristics of the longitudinal wavenumber spectral components in coupling the lower and upper atmosphere. Over a period of approximately 60 days, as the TIMED satellite both ascends and descends through orbital nodes, SABER is able to collect data sampled at almost a full 24 hours of local solar time. Figure 1 presents a local time (LT) series during a 7-year interval taken on the ascending (red dots) and descending (blue dots) orbit nodes at the equatorial latitude and at the $100 \mathrm{~km}$ altitude.

The TIMED/SABER observations are downloaded from the Web 


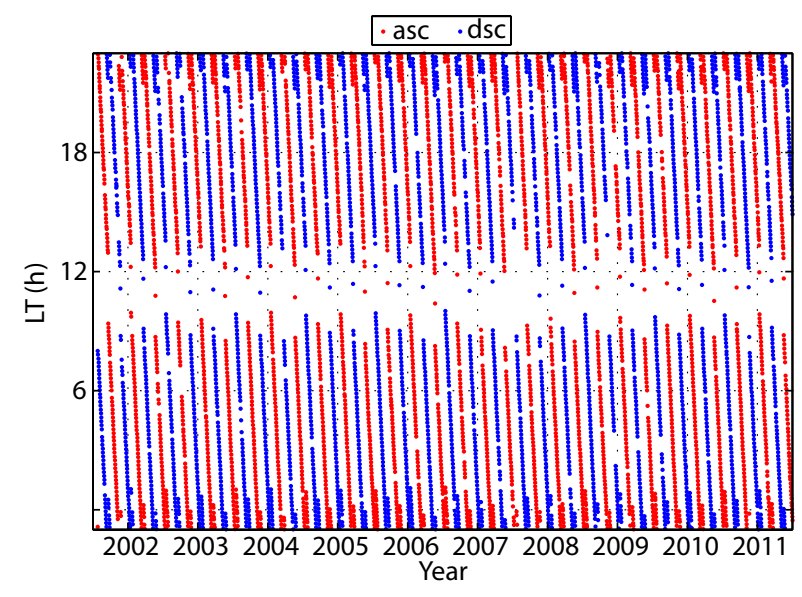

Figure 1. The LT series of SABER measurements by the TIMED satellite taken on the ascending (asc) and descending (dsc) orbit nodes at the equatorial latitude and at $100 \mathrm{~km}$ altitude.

site: http://saber.gats-inc.com/. More details about the instrument and recent results are given by Killeen et al., (2006) and Remsberg et al. (2008).

In the present study, we analyze Saber data, version 2, from both ascending and descending orbital nodes in the altitude range between 70 and $110 \mathrm{~km}$ and the latitude range between $45^{\circ} \mathrm{N}$ and $45^{\circ} \mathrm{S}$, collected during 2002-2012.

\subsection{Wavenumber Spectrums Analysis}

We have developed a technique to decompose the atmospheric waves of different longitudinal wavenumbers, based on wavenumber spectral analysis. Using this technique, we express daily temperature data by the composition of their wavenumber spectral components $W N_{k}$, where $W_{0}(\varphi, z, t, d)$ is the daily average of temperature $\left(T_{0}\right) ; t$ indicates LT and $d$ denotes the integer day numbers (UT days); $\lambda$ is the longitude and $z$ indicates altitude; $\varphi$ denotes latitude; $k=(1,2, \cdots, 6)$ denotes the longitudinal wavenumber; and $A_{k}(\varphi, z, t, d)$ and $\Phi_{k}(\varphi, z, t, d)$ are the amplitudes and phases of the spectral components $W_{k}(\varphi, z, t, d)$, respectively:

$$
\begin{gathered}
T(\lambda, \varphi, z, t, d)=W N_{0}(\varphi, z, t, d)+\sum W N_{k}(\varphi, z, t, d), \\
\text { where, } W N_{k}=A_{k}(\varphi, z, t, d) \cdot e^{i \cdot 2 \pi \cdot\left(-k \lambda+\Phi_{k}(\varphi, z, t, d)\right)} .
\end{gathered}
$$

The top plot of Figure 2 is an example of the temperature data from July 31, 2004, at the equatorial latitude $(\varphi=0)$ and at the altitude of $100 \mathrm{~km}$, represented as a distribution of longitude $\lambda$. For a single-fit-using equation, we use a horizontal grid spacing of 15 or 16 orbits a latitude cycle to extract the spectral components. The bottom plot of Figure 2 presents the deduced wavenumber spectral amplitudes $A_{k}$ from the top temperature data, represented as a wavenumber distribution $k$. It is obvious in Figure 2 that wave number $4(k=4) W N_{4}$ dominates the wavenumber spectral components in temperature $(T)$. As suggested by previous research, the $W N_{k}$ components are the strongest spectrum components in the MLT region as well as in the thermosphere and ionosphere (e.g., Sagawa et al., 2005; Immel et al., 2006; Wan W et al., 2008; Liu $\mathrm{HX}$ et al., 2009). Hence, among these wavenumber spectral components, we are mainly interested in the wave number $4(k=4)$
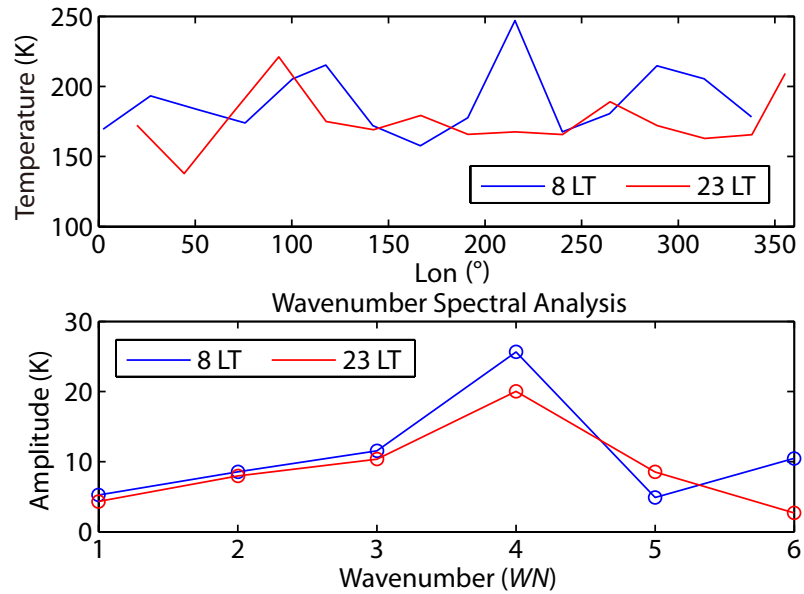

Figure 2. The top plot is the temperature in July 31,2004 , along the equator and at $100 \mathrm{~km}$ altitude; the bottom plot is the wavenumber spectral analysis. The red line is ascending (asc) node and the blue line is descending (dsc).

component $\mathrm{WN}_{4}$.

\section{Results}

SABERITIMED observations provide the daily temperature data analyzed here; these data have horizontal and vertical resolution of $2.5^{\circ}$ latitude by $2 \mathrm{~km}$ height. In addition, for each local time $t$ and each day number $d$, the amplitudes $A_{k}$ of the wavenumber spectral components $W N_{k}$ are then derived from the daily temperature data.

\subsection{Wavenumber Spectral Components}

Figure 3 shows the mean distribution of the amplitudes $A_{k}$ of the main wavenumber spectral components, which are further averaged among different years (2002-2012), as a distribution in the plane of latitude $\varphi$ vs height. From top to bottom and from left to right the plots refer the wavenumber $k=(1,2,3,4,5,6)$, respectively. It is also obvious in Figure 3, as well as in Figure 2, that the wavenumber spectral component $W N_{4}$ is quite remarkable among the different spectrum components in temperature $(T)$.

It should be noticed that the wavenumber components $W N_{k}$ in temperature present the convergent tendency, that is, wavenumber spectral amplitudes $A_{k}$ decrease as the wavenumber $k$ increases, as shown in Figure 3. In addition, the wavenumber component $W N_{4}$ are obvious, as illustrated in the bottom left plot of Figure 3. The wavenumber spectral amplitudes $A_{3}$ are a little larger, as seen in the top right plot of Figure 3, which would be consistent with the $W N_{3}$ of the total electron content (TEC) in the EIA region (Mu WF et al., 2010).

As seen in the top plots of Figure 3, the wavenumber component $W N_{1}$ is strongest at the altitudes range from 84 to $90 \mathrm{~km}$ around the equator; it is stronger at $\pm 30^{\circ}$. The amplitudes at high-mid latitudes are larger than that at low-latitude. The amplitudes $A_{2}$ of the second wavenumber component are largest at $85 \mathrm{~km}$ along the equator. Next, the wavenumber component $W N_{3}$ is strong from 100 to $110 \mathrm{~km}$ at mid-low latitudes in the northern hemi- 


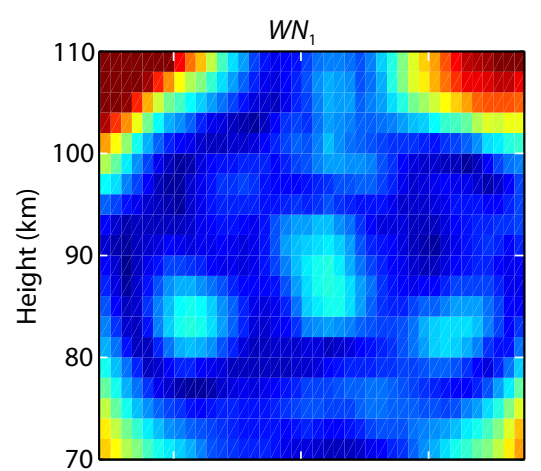

$\mathrm{WN}_{4}$

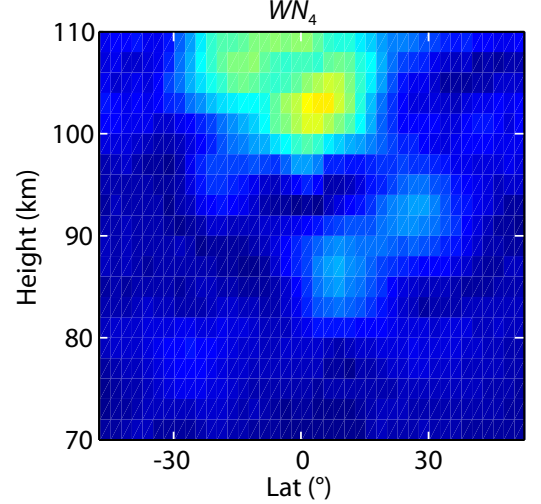

$W N_{2}$

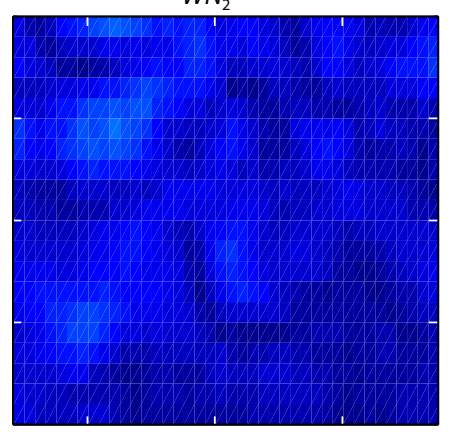

$W N_{5}$

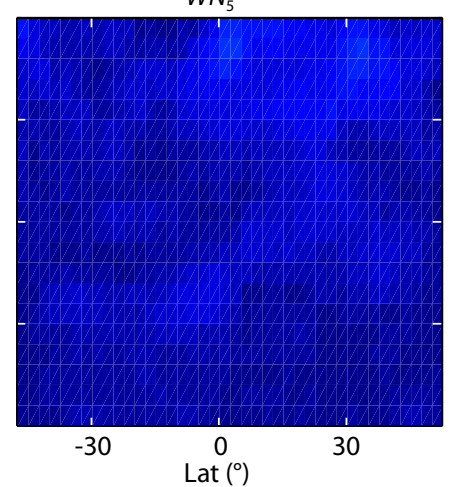

$W N_{3}$

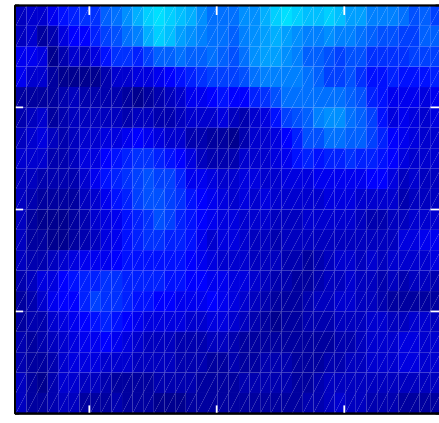

$W N_{6}$

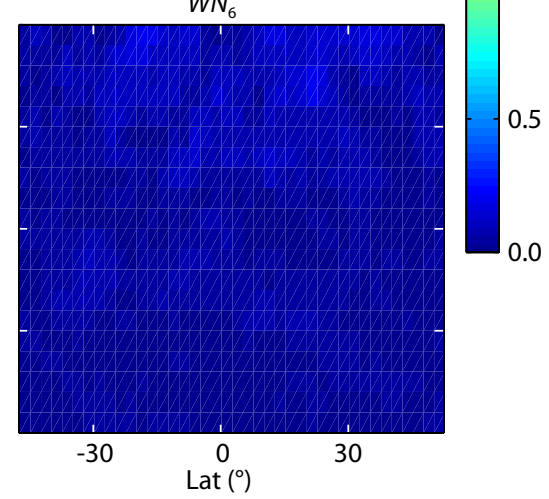

Figure 3. The average amplitudes $A_{k}$ from 2002 to 2012 of the main wavenumber spectral components are presented as height $z$ vs. latitude $\varphi$. The wavenumbers $k=1,2,3,4,5,6$, are presented in order from top to bottom.

sphere. As shown in the bottom left plots of Figure 3, the wavenumber component $W N_{4}$ is stable and strong around $100 \mathrm{~km}$ altitude and at the low-latitudes; i.e., the amplitude may reach to $1.2 \mathrm{~K}$, and the (relatively weak - it may reach only to $0.8 \mathrm{~K}$ ) peak amplitude occurs at $80-90 \mathrm{~km}$. The wavenumber components $W N_{5}$ and $W N_{6}$ are weaker in the MLT region.

Hence, among these wavenumber spectral components, we are mainly interested in the wavenumber component $W N_{4}$. The meteorological (short period variation) characteristics of the wavenumber spectral component $W N_{4}$ will be presented in the next section.

\subsection{Wavenumber-4 Spectral Component $W N_{4}$}

In this paper, we focus on wavenumber spectral component $W N_{4}$ in the atmospheric parameter $(T)$. For lack of daily temperature data, previous research into annual and inter-annual temperature variation focused on analysis of the climatological characteristics of the wavenumber components. Now, we reverse that approach by taking the component $W N_{4}$ for example, presenting its climatological (annual and inter-annual variation) and meteorological (short period variation) characteristics by using the now-plentiful daily temperature data. Figures 4 and Figure 5 show the yearly variations of the component $W_{4}$; Figures 6 and 8 illustrate the component $W_{4}$ which is smoothed with a running window of 1month's length; finally, Figures 7 and 9 show the day-to-day variation of $W_{4}$.

Take the spectral component $W N_{4}$ at $100 \mathrm{~km}$ altitude for an example; the short-period variations of the wavenumber spectral amplitudes $A_{4}$ in temperature $(T)$ at $100 \mathrm{~km}$ altitude, from 2002 to
2012 each year, are illustrated in Figure 4. As can be seen in Figure 4, as well as in the left bottom plot of Figure 3, the wavenumber spectral amplitudes $A_{4}$ present a remarkable annual variation at the low-latitudes: $A_{4}$ is larger in J-months (May, June, July and August), i.e., the spectral amplitudes $A_{4}$ may reach $6 \mathrm{~K}$ in August, as shown in the third-row plot of Figure 4 . Similar to Figure 4, the short period variations of the wavenumber spectral component $W N_{4}$ in temperature $(T)$ along the equator are shown in Figure 5. The amplitudes $A_{4}$ of the component are larger around $100 \mathrm{~km}$ altitudes, especially during J-months, as illustrated in the left bottom plot of Figures 3 and 5.

In order to analyze, in detail, the day-to-day variations of the wavenumber spectral components in the MLT region, as well as to compare the annual variation of the wavenumber spectral component $W N_{4}$ with results of previous research, the component $W N_{4}$ is smoothed with a running window of 1-month. Similar to Figures 4 and 5, Figures $6 a$ bb, $8 a$, and $8 b$ show the wavenumber spectral component $W N_{4}$ at $100 \mathrm{~km}$ and along the equator; i. e., the amplitude $A_{4}$ and the phase $\Phi_{4}$, respectively.

As illustrated in Figure $6 \mathrm{a}$, the spectral component $W N_{4}$ are strong at the low latitudes during the period of boreal summer to autumn, and present a weak peak in March at the mid-latitudes. Obviously, the yearly variation of the wavenumber spectral component $W N_{4}$ at the low-latitudes is highly dependent upon the nonmigrating tide DE3; this observation agrees with previous studies (e.g., Wu Q et al., 2008; Friedman et al., 2009; Oberheide et al., 2011). Additionally, the peak of the wavenumber spectral component $W N_{4}$ in summer is obviously divided into two peaks. For instance, the spectral amplitudes $A_{4}$ are larger in July and Septem- 

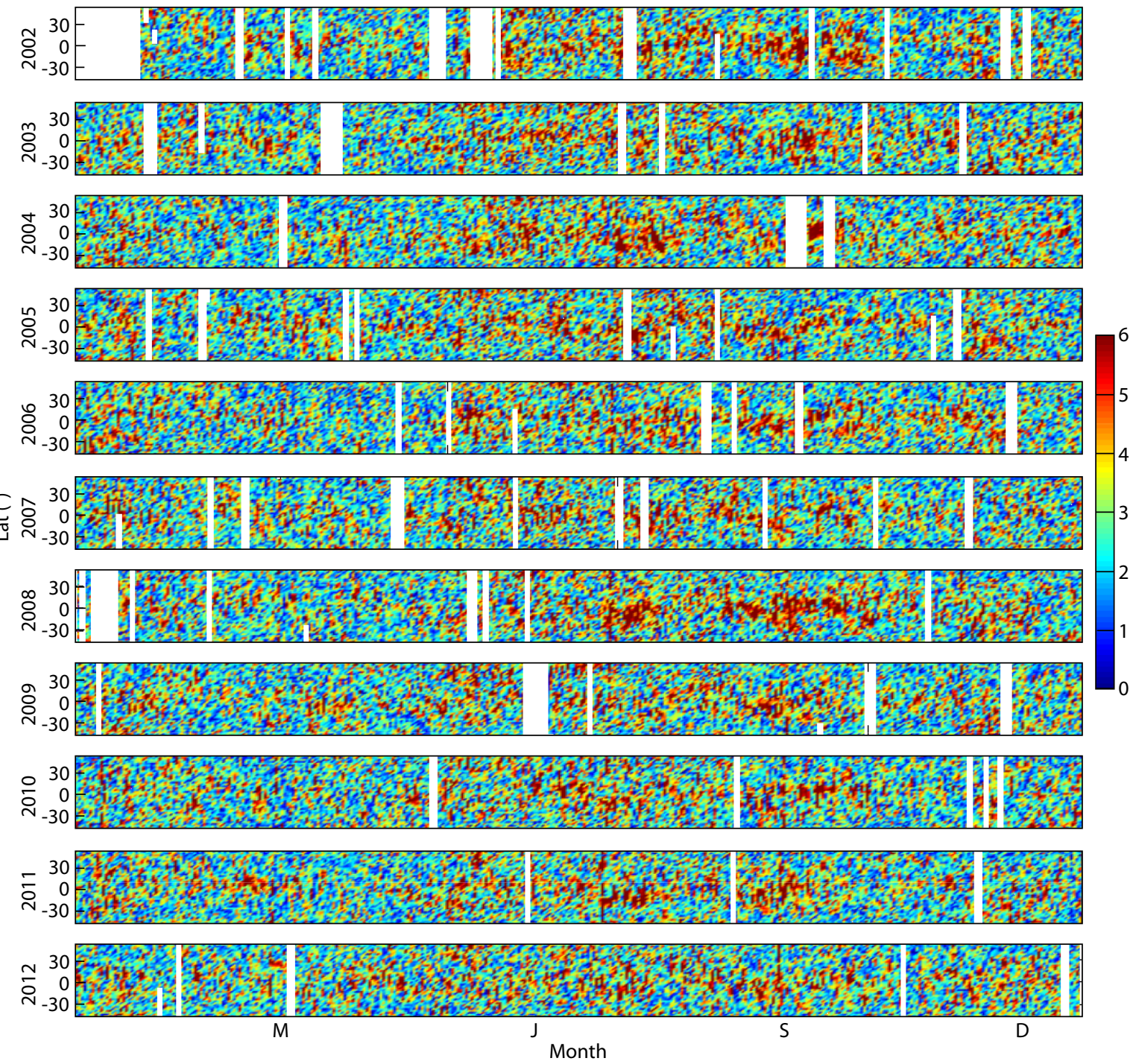

Figure 4. The wavenumber spectral amplitude $A_{4}$ at the altitude of $100 \mathrm{~km}$. From top to bottom are data for years $=2002,2003, \ldots, 2012$, respectively.

ber. Additionally, a weak peak of the $W N_{4}$ occurs in March at the mid-latitudes, which matches the variation of SE2 at the MLT altitudes (Pancheva et al., 2010; Oberheide et al., 2011). As to Figure $6 \mathrm{~b}$, the spectral phases $\Phi_{4}$ are stable when the corresponding amplitude is strong enough (i.e., in a J-month), but it is much noisier when amplitudes are weaker. This phenomenon is similar to the variation of DE3 in the MLT region (Wan W et al., 2010). In addition, as shown in Figure $6 \mathrm{~b}$, the spectral phases have a cycle of about two months.

As seen in Figure $8 \mathrm{a}$, the spectral amplitudes $A_{4}$ along the equator are larger above $100 \mathrm{~km}$ altitude; and in April, June, and July; i.e., we observe that the amplitude reaches $4 \mathrm{~K}$ in July 2008 at $100 \mathrm{~km}$. In addition, as illustrated in Figure $8 \mathrm{~b}$, the spectral phases $\Phi_{4}$ are stable at the MLT altitudes, especially in J-months. The wave length along the equator is about $30 \mathrm{~km}$, as shown in Figure 8b.

In this work, the day-to-day variation of the wavenumber spectral component $W N_{4}$ is represented by the difference between suc- cessive daily averages, smoothed with a running window of 1-month, of the daily $W_{4}$ component. This day-to-day variation of the smoothed average wavenumber spectral component $W N_{4}$ is shown in Figures 7a, 7b, 9a, and 9b; i.e., the amplitude $A_{4}$ and the phase $\Phi_{4}$, respectively. As seen in Figure $7 \mathrm{a}$, the amplitudes of the day-to-day variation are also obvious in J-months and at the lowlatitudes. We report that the day-to-day variation has peak amplitudes in September at the low-latitudes in the southern hemisphere. Also, as Figure 9a indicates, the day-to-day variation of the wavenumber spectral component is most remarkable around $100 \mathrm{~km}$ along the equator.

\section{Discussion}

From the above analysis of data from the TIMED satellite over a range of the atmospheric parameter $(T)$, we conclude that the most prominent feature of the wavenumber spectrum is the fourpeaked longitudinal structure $\left(W N_{4}\right)$. The observed yearly variation of the spectral component $W N_{4}$ in Figures 3 and 4 were almost fully emulated by DE3 at the low-latitudes and by SE2 at the 

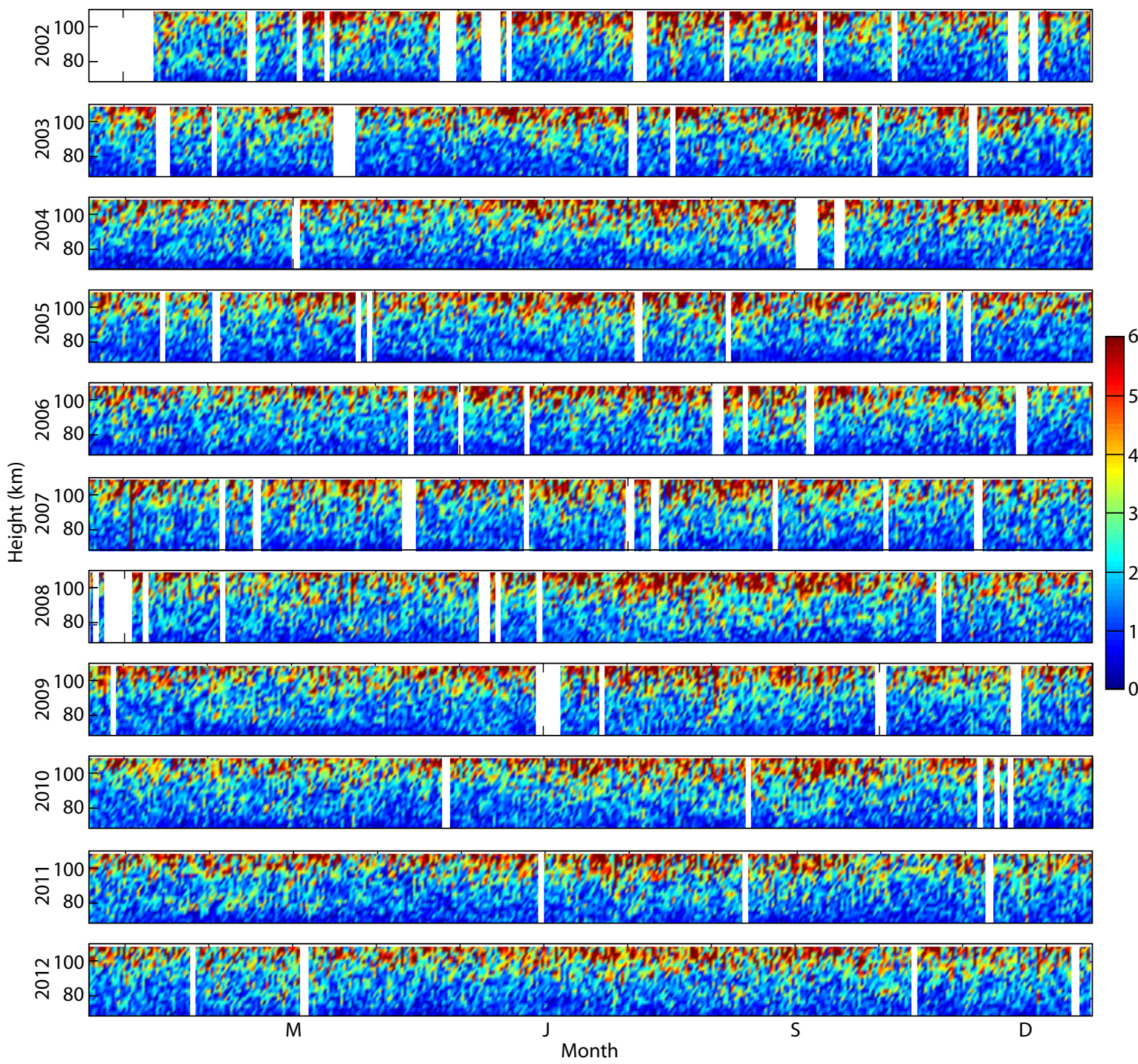

Figure 5. Same as Figure 4 but for the wavenumber spectral amplitude $A_{4}$ along the equator.

mid-latitudes.

Similarly, the analysis demonstrates that DE3 is intimately connected at low latitudes with the longitudinal distribution, by topography and land-sea difference, of the predominant wavenumber, which is wavenumber 4. (e.g., Forbes et al., 2006; Pancheva et al., 2010; Oberheide et al., 2009, 2011). As suggested by previous studies, the longitudinal wavenumber spectral component $W N_{k}$ in the ionospheric $F$ region may originate from longitudinal modulation of the latitudinal symmetric modes; the main contributing tide is believed to be the DE3 tide (Wan W et al., 2010). Comparing our work with the above results, we note that the yearly variation of the spectral component $W N_{4}$ is completely consistent with that in the temperature fluctuations of DE3 at the low latitudes.

Moreover, observational evidence supports the hypothesis that SE2 may be an important source of the wavenumber-4 structure at the mid-latitude in the ionosphere and thermosphere (e.g., Oberheide et al., 2007; Forbes et al., 2008; Hagan et al., 2009; England et al., 2010; Häusler et al., 2010; Oberheide et al., 2011;
Pancheva and Mukhtarov, 2012; Chang LC et al., 2013). Our results above suggest that the mid-latitude peak of the spectral component $W N_{4}$ may correspond to the SE2 tide at the middle latitudes.

Hence, we suggest that the wavenumber spectrum $W N_{4}$ is determined primarily by the DE3 tide at the low-latitudes and by the SE2 tide at the mid-latitudes. In addition, the abundant observation data available from the TIMED satellite have allowed analysis of the local time (LT) variations of the wavenumber spectral phases $\Phi_{4}$ at the MLT altitudes. Statistical analysis of these data finds that the phases of the component are regular when the amplitudes are strong. Figure 10 shows two examples of the average phases $\Phi_{4}$, represented as a distribution of LT. The top plot of Figure 10 presents the phases $\Phi_{4}$ at the altitude of $100 \mathrm{~km}$ along the equator in the J-months (May, June, July and August); the bottom plot presents phases in March at the $110 \mathrm{~km}$ altitude at $30^{\circ} \mathrm{N}$ latitude. As seen in Figure 10, in an LT period the phase variation is obviously linear. We suppose that the wavenumber component $W_{4}$ may originate mainly from the longitudinal modulation of one single mode. In addition, as illustrated in the top and bottom 


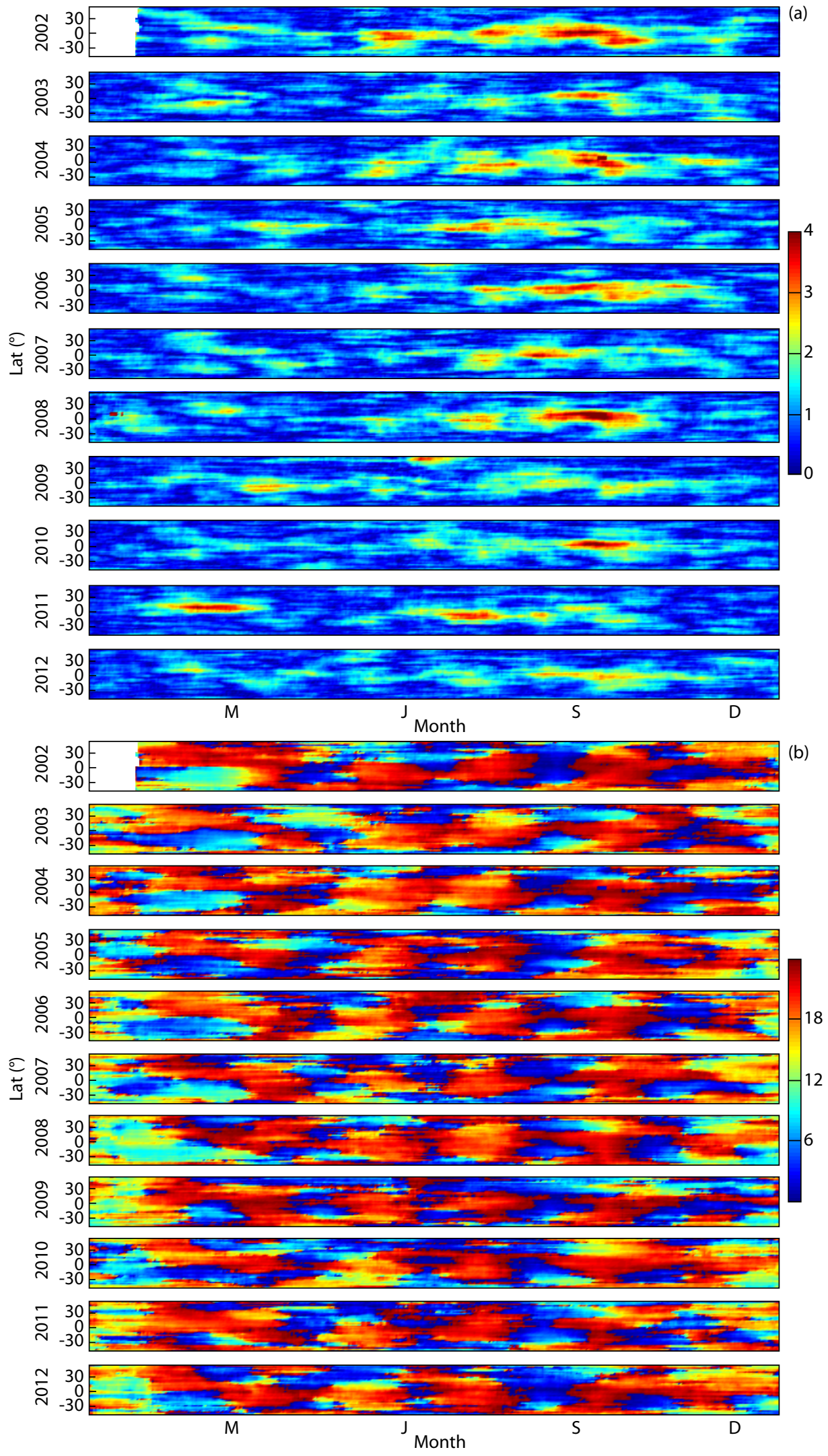

Figure 6. (a) Same as Figure 4 but for the wavenumber spectral amplitude $A_{4}$ at the altitude of $100 \mathrm{~km}$, smoothed with a running window of length equal to one-month of daily data. (b) Same as Figure 4 but for the wavenumber spectral phase $\Phi_{4}$ at the altitude of $100 \mathrm{~km}$, smoothed with a running window of length equal to one-month of daily data. 


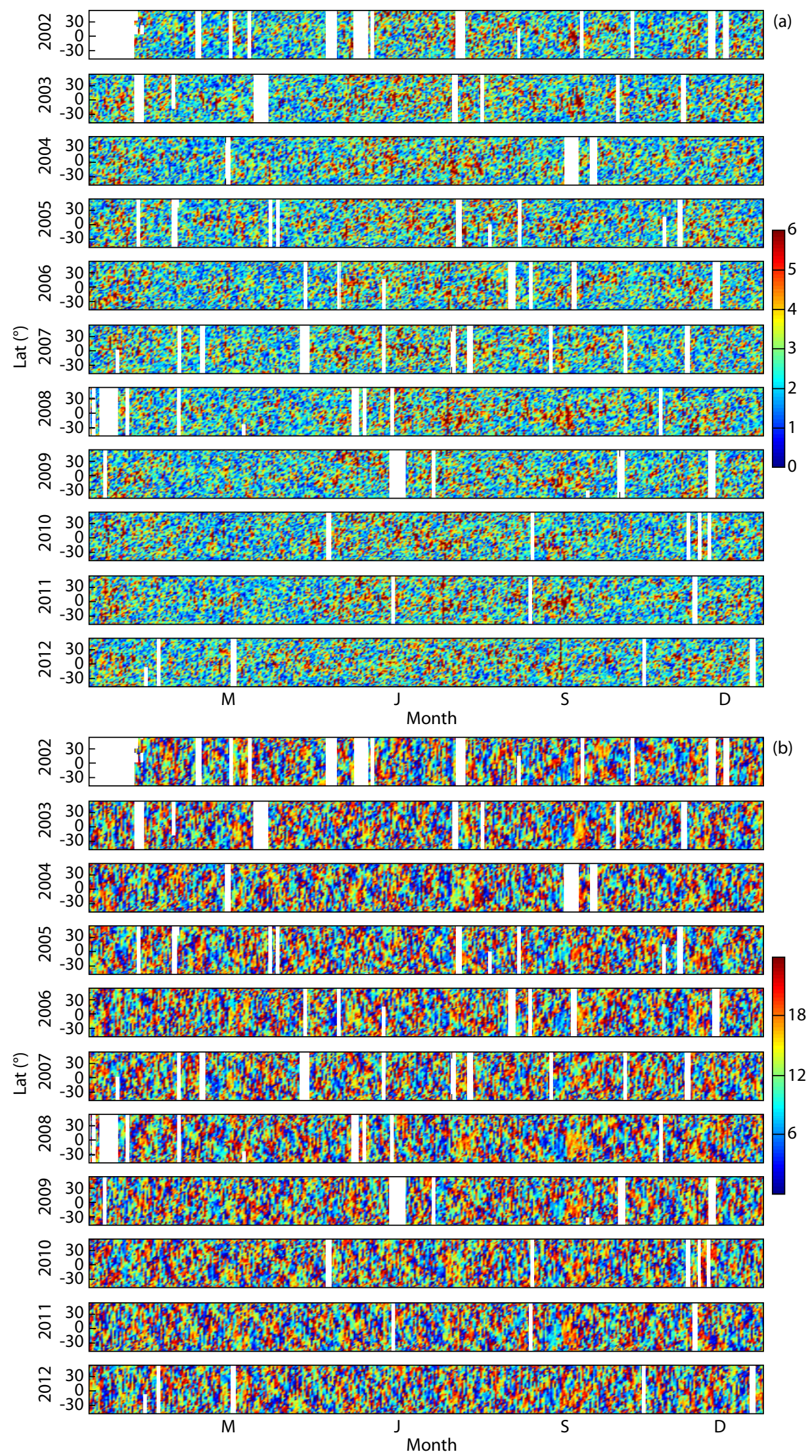

Figure 7. (a) Same as Figure 4 but for the day-to-day variation of the wavenumber spectral amplitude $A_{4}$ at the altitude of $100 \mathrm{~km}$. (b) Same as Figure 4 but for the day-to-day variation of the wavenumber spectral phase $\Phi_{4}$ at the altitude of $100 \mathrm{~km}$. 


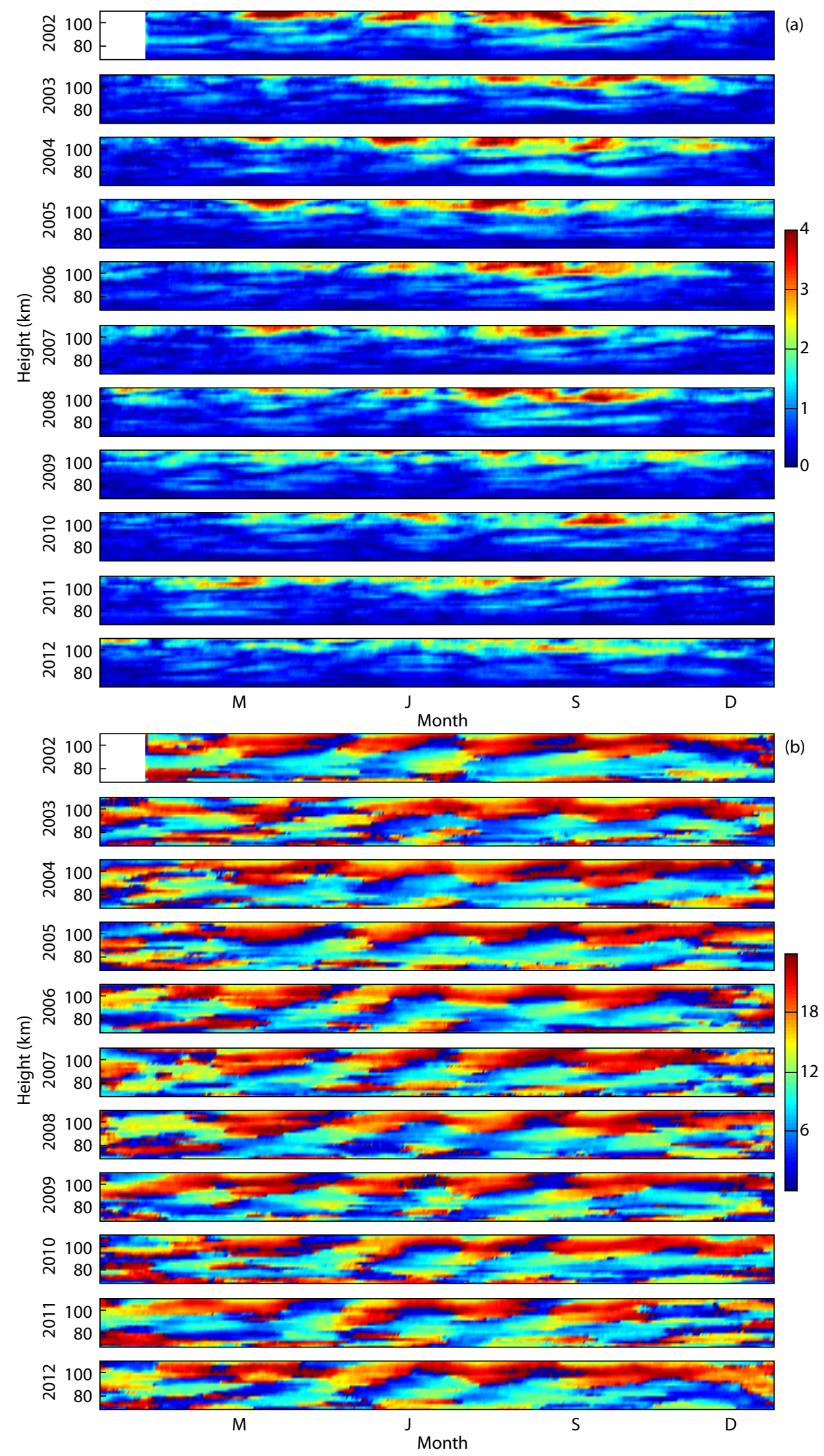

Figure 8. (a) Same as Figure 4 but for the wavenumber spectral altitudes $A_{4}$ along the equator. (b) Same as Figure 4 but for the wavenumber spectral phase $\Phi_{4}$ along the equator. 


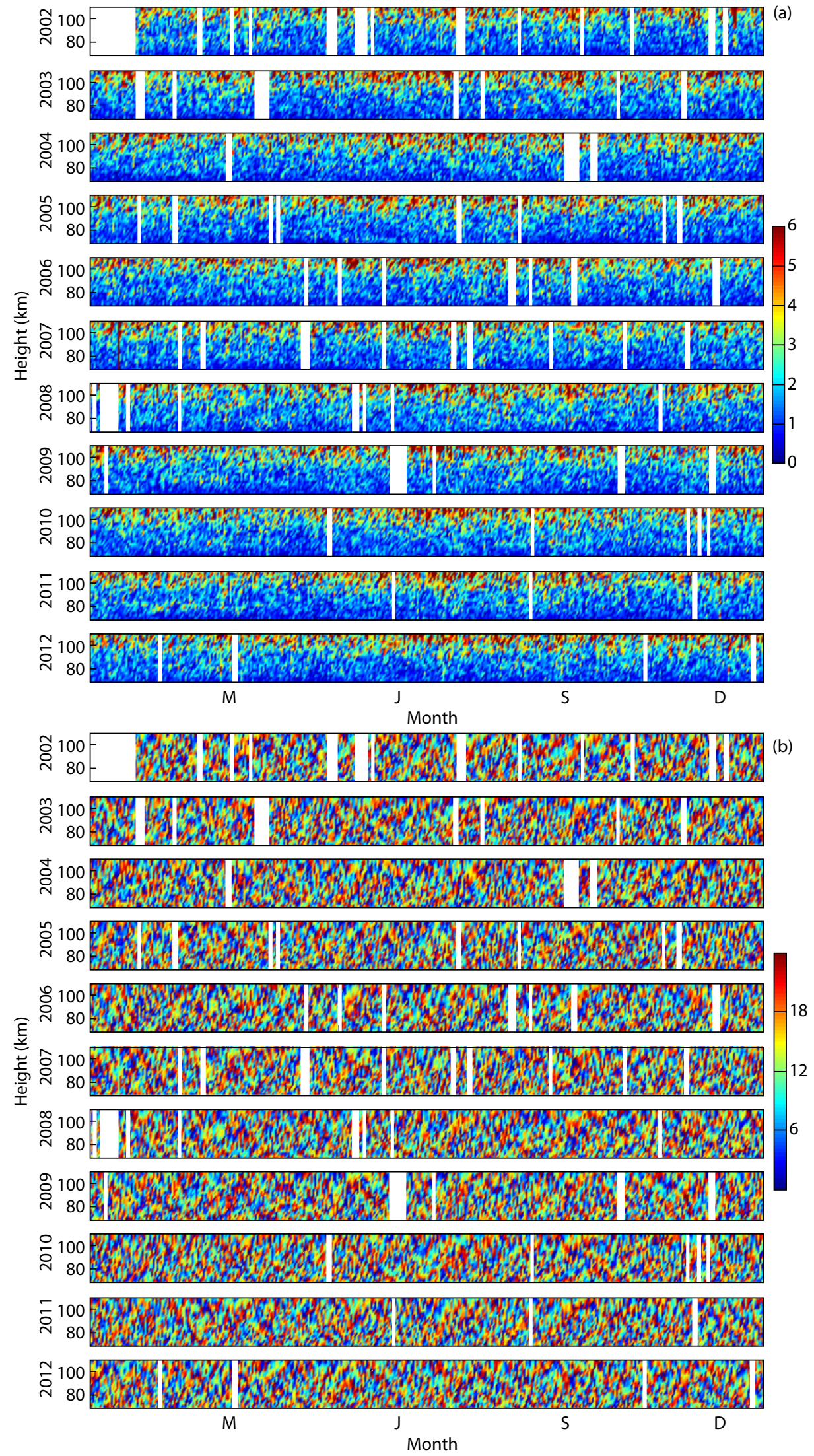

Figure 9. (a) Same as Figure 4 but for the day-to-day variation of the wavenumber spectral amplitude $A_{4}$ along the equator. (b) Same as Figure 4 but for the day-to-day variation of the wavenumber spectral phase $\Phi_{4}$ along the equator. 

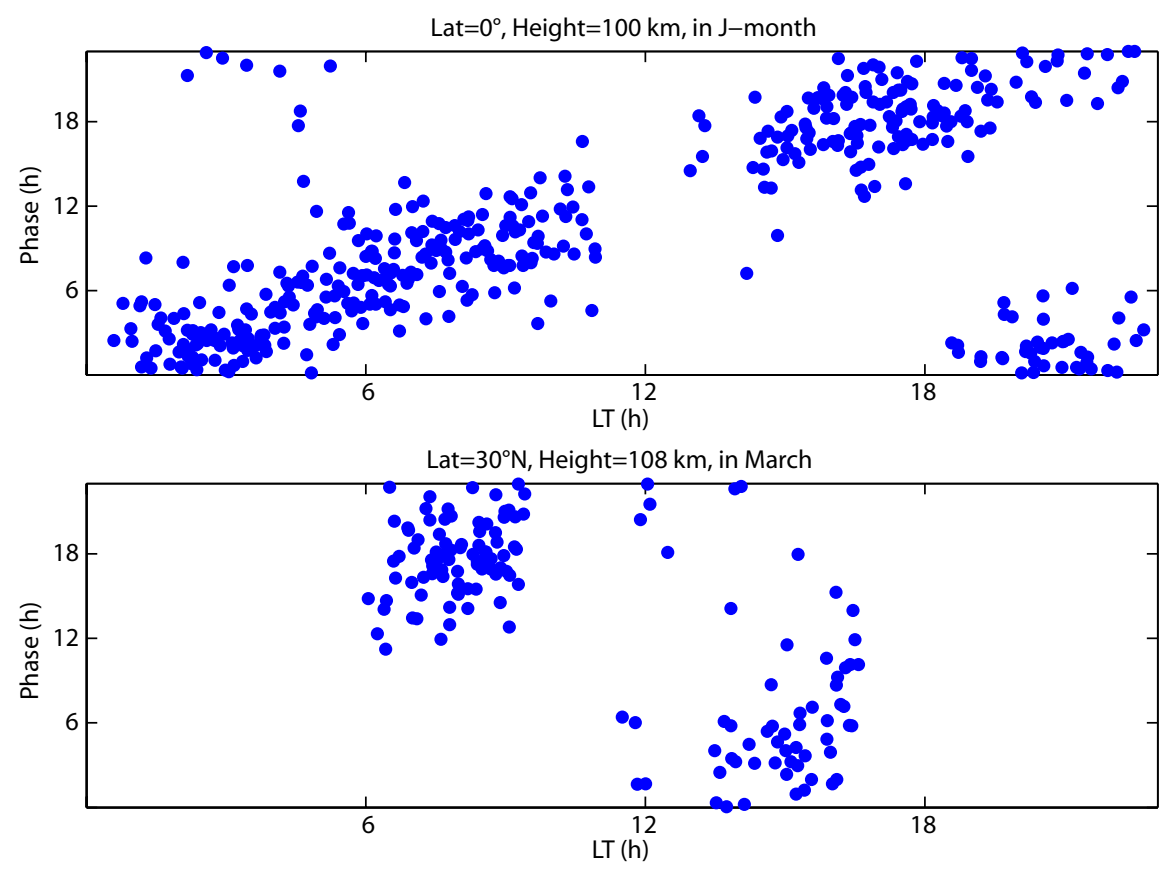

Figure 10. The average phases $\Phi_{4}$ of the wavenumber 4 component are presented in the plane of local solar time. The top plot is the J-month average phases along the equator at the altitude of $100 \mathrm{~km}$, and the bottom plot is the March average phases in $30^{\circ} \mathrm{N}$ at $110 \mathrm{~km}$ altitude.

plots of Figure 10, the estimated period of $24 \mathrm{LT}$ and $12 \mathrm{LT}$, respectively, demonstrate that the single mode should be a diurnal tide and a semi-diurnal tide, which exhibit four wave peaks when seen from a Sun-Synchronous view.

Therefore, we conclude that the eastward propagating diurnal tide with zonal wave number 3 (DE3), at the low-latitudes, and the eastward propagating semi-diurnal tide with zonal wave number 2 (SE2) at the mid-latitudes, are the primary explanation for the wavenumber spectrum $W N_{4}$. Similarly, our analysis demonstrates that DE3 and SE2 are intimately connected with the predominant wavenumber 4 longitude distribution of topography and land-sea difference at the low-latitudes (e.g., Forbes et al., 2006; Oberheide et al., 2009, 2011; Pancheva et al., 2010) and at the mid-latitudes. (e.g., Oberheide et al., 2007; Forbes et al., 2008; Hagan et al., 2009; England et al., 2010; Häusler et al., 2010; Oberheide et al., 2011; Pancheva and Mukhtarov, 2012; Chang LC et al., 2013).

\section{Summary and Conclusions}

In the present work, TIMED $\backslash$ SABER observation data have been used to obtain longitudinal wavenumber spectral components $W N_{k}$ of the atmospheric parameter $(T)$ and to investigate the wavenumber-4 spectral component $W N_{4}$ at the MLT altitudes (70-110 km). We report that the most prominent wavenumber spectral component is the component $W N_{4}$. The main results are outlined as follows:

(1) The variations of the wavenumber spectral components $W N_{k}$ in Temperature $(T)$ are observed to be strong in the MLT region and at the low-latitudes. Among the components, $W N_{4}$ is strongest; $W N_{1}$ is second-strongest. $W N_{4}$ is stronger around $100 \mathrm{~km}$ altitude and at the low-latitudes. The wavenumber spectral amplitudes $A_{1}$ are larger along the equator and at mid-latitudes in the altitude range of $80-90 \mathrm{~km}$.

(2) Using long duration temperature data, the climatological (annual and inter-annual variation) characteristics of the wavenumber spectral component $W N_{4}$ are presented. The yearly variations imply the possibility that the component $W N_{4}$ in temperature is dependent at the low latitudes primarily on the diurnal, eastward, wavenumber 3 nonmigrating tide DE3, and on the semi-diurnal, eastward, wavenumber 2 nonmigrating tide SE2 at the mid-latitudes. In addition, we find that the wavenumber spectral component $W N_{4}$ undergoes a remarkable short period variation: the peak spectral amplitude $A_{4}$ in temperature occurs primarily in boreal summer and autumn at the low-latitudes and above $100 \mathrm{~km}$ altitudes.

From the above results, we conclude that the climatological characteristic of the wavenumber spectral components is consistent with that of the non-migrating tides in temperature. In addition, the meteorological characteristic of the wavenumber spectral component $W N_{4}$ shows two peak amplitudes during the boreal summer and autumn, i.e., July and September, which may originate from the longitudinal modulation of the DE3 tide at the lowlatitudes and shows a weak peak amplitude in March, which may originate from the longitudinal modulation of the SE2 tide at the mid-latitudes. Thus, we suggest that the non-migrating tides DE3 and SE2 should be acknowledged as the origins of the observed longitudinal wavenumber spectral component $W N_{4}$ at, respectively, the low- and the mid-latitudes in the MLT region.

\section{Acknowledgments}

The TIMED/SABER temperature observations were provided through the website http://saber.gats-inc.com. The present work is supported by National Science Foundation of China (41604138, 
Häusler, K., and Lühr, H. (2009). Nonmigrating tidal signals in the upper thermospheric zonal wind at equatorial latitudes as observed by CHAMP. Ann. Geophys., 27(7), 2643-2652. https://doi.org/10.5194/angeo-27-26432009

\section{References}

Bruinsma, S. L., and Forbes, J. M. (2010). Anomalous behavior of the thermosphere during solar minimum observed by CHAMP and GRACE. J. Geophys. Res. Space Phys., 115(A11), A11323. https://doi.org/10.1029/2010JA015605

Burrage, M. D., Hagan, M. E., Skinner, W. R., Wu, D. L., and Hays, P. B. (1995). Long-term variability in the solar diurnal tide observed by HRDI and simulated by the GSWM. Geophys. Res. Lett., 22(19), 2641-2644. https://doi.org/10.1029/95GL02635

Chang, L. C., Lin, C. H., Yue, J., Liu, J. Y., and Lin, J. T. (2013). Stationary planetary wave and nonmigrating tidal signatures in ionospheric wave 3 and wave 4 variations in 2007-2011 FORMOSAT-3/COSMIC observations. J. Geophys. Res. Space Phys., 118(10), 6651-6665. https://doi.org/10.1002/jgra.50583

Chapman, S., and Lindzen, R. S. (1970). Atmospheric Tides: Thermal and Gravitational. Netherlands: Springer. https://doi.org/10.1007/978-94-0103399-2

Chen, Z. Y., and Lü, D. R. (2007). Seasonal variations of the MLT tides in $120^{\circ} \mathrm{E}$ meridian. Chinese J. Geophys. (in Chinese), 50(3), 691-700.

England, S. L., Immel, T. J., Sagawa, E., Henderson, S. B., Hagan, M. E., Mende, S. B., Frey, H. U., Swenson, C. M., and Paxton, L. J. (2006). Effect of atmospheric tides on the morphology of the quiet time, postsunset equatorial ionospheric anomaly. J. Geophys. Res. Space Phys., 111(A10), A10S19. https://doi.org/10.1029/2006JA011795

England, S. L., Immel, T. J., Huba, J. D., Hagan, M. E., Maute, A., and DeMajistre, R. (2010). Modeling of multiple effects of atmospheric tides on the ionosphere: an examination of possible coupling mechanisms responsible for the longitudinal structure of the equatorial ionosphere. J. Geophys. Res. Space Phys., 115(A5), A05308. https://doi.org/10.1029/2009JA014894

Forbes, J. M., Russell, J., Miyahara, S., Zhang, X., Palo, S., Mlynczak, M., Mertens, C. J., and Hagan, M. E. (2006). Troposphere-thermosphere tidal coupling as measured by the SABER instrument on TIMED during July-September 2002. J. Geophys. Res. Space Phys., 111(A10), A10S06. https://doi.org/10.1029/2005JA011492

Forbes, J. M., and Wu, D. (2006). Solar tides as revealed by measurements of mesosphere temperature by the MLS experiment on UARS. J. Atmos. Sci., 63(7), 1776-1797. https://doi.org/10.1175/JAS3724.1

Forbes, J. M., Zhang, X., Palo, S., Russell, J., Mertens, C. J., and Mlynczak, M. (2008). Tidal variability in the ionospheric dynamo region. J. Geophys. Res. Space Phys., 113(A2), A02310. https://doi.org/10.1029/2007JA012737

Friedman, J. S., Zhang, X. L., Chu, X. Z., and Forbes, J. M. (2009). Longitude variations of the solar semidiurnal tides in the mesosphere and lower thermosphere at low latitudes observed from ground and space. J. Geophys. Res. Atmos., 114(D11), D11114. https://doi.org/10.1029/2009JD011763

Garcia, R. R., Lieberman, R., Russell III, J. M., and Mlynczak, M. G. (2005). Largescale waves in the mesosphere and lower thermosphere observed by SABER. J. Atmos. Sci., 62(12), 4384-4399. https://doi.org/10.1175/JAS3612.1

Gu, S. Y., Li, T., Dou, X. K., Wu, Q., Mlynczak, M. G., and Russell III, J. M. (2013). Observations of quasi-two-day wave by TIMED/SABER and TIMED/TIDI. J. Geophys. Res. Atmos., 118(4), 1624-1639. https://doi.org/10.1002/jgrd.50191

Hagan, M. E., and Forbes, J. M. (2002). Migrating and nonmigrating diurnal tides in the middle and upper atmosphere excited by tropospheric latent heat release. J. Geophys. Res. Atmos., 107(D24), ACL 6-1-ACL 6-15. https://doi.org/10.1029/2001JD001236

Hagan, M. E., and Forbes, J. M. (2003). Migrating and nonmigrating semidiurnal tides in the upper atmosphere excited by tropospheric latent heat release. J. Geophys. Res. Space Phys., 108(A2), 1062. https://doi.org/10.1029/2002JA009466

Hagan, M. E., Maute, A., and Roble, R. G. (2009). Tropospheric tidal effects on the middle and upper atmosphere. J. Geophys. Res. Apce Phys., 114(A1), A01302. https://doi.org/10.1029/2008JA013637

Hartman, W. A., and Heelis, R. A. (2007). Longitudinal variations in the equatorial vertical drift in the topside ionosphere. J. Geophys. Res. Space Phys., 112(A3), A03305. https://doi.org/10.1029/2006JA011773

Häusler, K., Lühr, H, Hagan, M. E., Maute, A., and Roble, R. G. (2010). Comparison of CHAMP and TIME-GCM nonmigrating tidal signals in the thermospheric zonal wind. J. Geophys. Res. Atmos., 115(D1), D00108.

https://doi.org/10.1029/2009JD012394

Hitchman, M. H., and Leovy, C. B. (1985). Diurnal tide in the equatorial middle atmosphere as seen in LIMS temperatures. J. Atmos. Sci., 42(6), 557-561. https://doi.org/10.1175/1520-0469(1985)042<0557:DTITEM>2.0.CO;2

Huang, F. T., and Reber, C. A. (2003). Seasonal behavior of the semidiurnal and diurnal tides, and mean flows at $95 \mathrm{~km}$, based on measurements from the High Resolution Doppler Imager (HRDI) on the Upper Atmosphere Research Satellite (UARS). J. Geophys. Res. Atmos., 108(D12), 4360. https://doi.org/10.1029/2002JD003189

Huang, F. T., and Reber, C. A. (2004). Nonmigrating semidiurnal and diurnal tides at $95 \mathrm{~km}$ based on wind measurements from the High Resolution Doppler Imager on UARS. J. Geophys. Res. Atmos., 109(D10), D10110. https://doi.org/10.1029/2003JD004442

Immel, T. J., Sagawa, E., England, S. L., Henderson, S. B., Hagan, M. E., Mende, S. B., Frey, H. U., Swenson, C. M., and Paxton, L. J. (2006). Control of equatorial ionospheric morphology by atmospheric tides. Geophys. Res. Lett., 33(15), L15108. https://doi.org/10.1029/2006GL026161

John, S. R., and Kumar, K. K. (2011). TIMED/SABER observations of global cold point mesopause variability at diurnal and planetary wave scales. J. Geophys. Res. Space Phys., 116(A6), A06314. https://doi.org/10.1029/2010JA015945

Khattatov, B. V., Geller, M. A., Yubin, V. A., and Hays, P. B. (1997). Diurnal migrating tide as seen by the high-resolution Doppler imager/UARS: 2 . Monthly mean global zonal and vertical velocities, pressure, temperature, and inferred dissipation. J. Geophys. Res. Atmos., 102(D4), 4423-4435. https://doi.org/10.1029/96JD03654

Kil, H., Oh, S. J., Kelley, M. C., Paxton, L. J., England, S. L., Talaat, E., Min, K. W., and Su, S. Y. (2007). Longitudinal structure of the vertical $\mathbf{E} \times \mathbf{B}$ drift and ion density seen from ROCSAT-1. Geophys. Res. Lett., 34(14), L14110. https://doi.org/10.1029/2007GL030018

Killeen, T. L., Wu, Q., Solomon, S. C., Ortland, D. A., Skinner, W. R., Niciejewski, R. J., and Gell, D. A. (2006). TIMED Doppler interferometer: Overview and recent results. J. Geophys. Res. Space Phys., 111(A10), A10S01. https://doi.org/10.1029/2005JA011484

Lin, C. H., Hsiao, C. C., Liu, J. Y., and Liu, C. H. (2007). Longitudinal structure of the equatorial ionosphere: Time evolution of the four-peaked EIA structure. J. Geophys. Res. Space Phys., 112(A12), A12305. https://doi.org/10.1029/2007JA012455

Liu, H. X., Yamamotom, M., and Lühr, H. (2009). Wave-4 pattern of the equatorial mass density anomaly: A thermospheric signature of tropical deep convection. Geophys. Res. Lett., 36(18), L18104. https://doi.org/10.1029/2009GL039865

Lühr, H., Häusler, K., and Stolle, C. (2007). Longitudinal variation of F region electron density and thermospheric zonal wind caused by atmospheric tides. Geophys. Res. Lett., 34(16), L16102. https://doi.org/10.1029/2007GL030639

Manson, A. H., Luo, Y., and Meek, C. (2002). Global distributions of diurnal and semi-diurnal tides: observations from HRDI-UARS of the MLT region. Ann. Geophys., 20(11), 1877-1890. https://doi.org/10.5194/angeo-20-1877-2002

McLandress, C., Rochon, Y., Shepherd, G. G., Solheim, B. H., Thuillier, G., and Vial, F. (1994). The meridional wind component of the thermospheric tide observed by WINDII on UARS. Geophys. Res. Lett., 21(22), 2417-2420. https://doi.org/10.1029/94GL02367

McLandress, C., Shepherd, G. G., and Solheim, B. H. (1996). Satellite observations of thermospheric tides: Results from the wind imaging interferometer on UARS. J. Geophys. Res. Atmos., 101(D2), 4093-4114. https://doi.org/10.1029/95JD03359

Miyoshi, Y., Jin, H., Fujiwara, H., Shinagawa, H., and Liu, H. X. (2012). Wave-4 structure of the neutral density in the thermosphere and its relation to 
atmospheric tides. J. Atmos. Sol.-Terr. Phys., 90-91, 45-51. https://doi.org/10.1016/j.jastp.2011.12.002

Mu, W. F., Wan, W. X., Ren, Z. P., and Xiong, J. G. (2010). Correlation between ionospheric longitudinal harmonic components and upper atmospheric tides. Chin. Sci. Bull., 55(35), 4037-4045. https://doi.org/10.1007/s11434-0104205-1

Mukhtarov, P., Pancheva, D., and Andonov, B. (2009). Global structure and seasonal and interannual variability of the migrating diurnal tide seen in the SABER/TIMED temperatures between 20 and $120 \mathrm{~km}$. J. Geophys. Res. Space Phys., 114(A2), A02309. https://doi.org/10.1029/2008JA013759

Oberheide, J., Wu, Q., Killeen, T. L., Hagan, M. E., and Roble, R. G. (2006). Diurnal nonmigrating tides from TIMED Doppler Interferometer wind data: Monthly climatologies and seasonal variations. J. Geophys. Res. Space Phys., 111(A10), A10S03. https://doi.org/10.1029/2005JA011491

Oberheide, J., Wu, Q., Killeen, T. L., Hagan, M. E., and Roble, R. G. (2007). A climatology of nonmigrating semidiurnal tides from TIMED Doppler Interferometer (TIDI) wind data. J. Atmos. Sol.-Terr. Phys., 69(17-18), 2203-2218. https://doi.org/10.1016/j.jastp.2007.05.010

Oberheide, J., and Forbes, J. M. (2008). Tidal propagation of deep tropical cloud signatures into the thermosphere from TIMED observations. Geophys. Res. Lett., 35(4), L04816. https://doi.org/10.1029/2007GL032397

Oberheide, J., Forbes, J. M., Häusler, K., Wu, Q., and Bruinsma, S. L. (2009). Tropospheric tides from 80 to $400 \mathrm{~km}$ : Propagation, interannual variability, and solar cycle effects. J. Geophys. Res. Atmos., 114(D1), D00105. https://doi.org/10.1029/2009JD012388

Oberheide, J., Forbes, J. M., Zhang, X., and Bruinsma, S. L. (2011). Wave-driven variability in the ionosphere-thermosphere-mesosphere system from TIMED observations: What contributes to the "wave 4"?. J. Geophys. Res. Space Phys., 116(A1), A01306. https://doi.org/10.1029/2010JA015911

Pancheva, D., Mukhtarov, P., and Andonov, B. (2010). Global structure, seasonal and interannual variability of the eastward propagating tides seen in the SABER/TIMED temperatures (2002-2007). Ann. Geophys., 46(3), 257-274. https://doi.org/10.1016/j.asr.2010.03.026

Pancheva, D., and Mukhtarov, P. (2012). Global response of the ionosphere to atmospheric tides forced from below: recent progress based on satellite measurements. Global tidal response of the ionosphere. Space Sci. Rev., 168(1-4), 175-209. https://doi.org/10.1007/s11214-011-9837-1
Remsberg, E. E., Marshall, B. T., Garcia-Comas, M., Krueger, D., Lingenfelser, G. S., Martin-Torres, J., Mlynczak, M. G., Russell III, J. M., Smith, A. K., ... Thompson, R. E. (2008). Assessment of the quality of the Version 1.07 temperatureversus-pressure profiles of the middle atmosphere from TIMED/SABER. J. Geophys. Res. Atmos., 113(D17), D17101. https://doi.org/10.1029/2008JD010013

Ren, Z. P., Wan, W. X., Liu, L. B., and Xiong, J. G. (2009). Intra-annual variation of wave number 4 structure of vertical $E \times \mathbf{B}$ drifts in the equatorial ionosphere seen from ROCSAT-1. J. Geophys. Res. Space Phys., 114(A5), A05308. https://doi.org/10.1029/2009JA014060

Sagawa, E., Immel, T. J., Frey, H. U., and Mende, S. B. (2005). Longitudinal structure of the equatorial anomaly in the nighttime ionosphere observed by IMAGE/FUV. J. Geophys. Res. Space Phys., 110(A11), A11302. https://doi.org/10.1029/2004JA010848

Wan, W., Liu, L., Pi, X., Zhang, M. L., Ning, B., Xiong, J., and Ding, F. (2008). Wavenumber-4 patterns of the total electron content over the low latitude ionosphere. Geophys. Res. Lett., 35(12), L12104. https://doi.org/10.1029/2008GL033755

Wan, W., Xiong, J., Ren, Z., Liu, L., Zhang, M. L., Ding, F., Ning, B., Zhao, B., and Yue, X. (2010). Correlation between the ionospheric WN4 signature and the upper atmospheric DE3 tide. J. Geophys. Res. Space Phys., 115(A11), A11303. https://doi.org/10.1029/2010JA015527

Wu, Q., Ortland, D. A., Killeen, T. L., Roble, R. G., Hagan, M. E., Liu, H. L., Solomon, S. C., Xu, J. Y., Skinner, W. R., and Niciejewski, R. J. (2008). Global distribution and interannual variations of mesospheric and lower thermospheric neutral wind diurnal tide: 2. Nonmigrating tide. J. Geophys. Res. Space Phys., 113(A5), A05309. https://doi.org/10.1029/2007JA012543

Xu, J. Y., Smith, A. K., Liu, H. L., Yuan, W., Wu, Q., Jiang, G. Y., Mlynczak, M. G., Russell III, J. M., and Franke, S. J. (2009). Seasonal and quasi-biennial variations in the migrating diurnal tide observed by Thermosphere, lonosphere, Mesosphere, Energetics and Dynamics (TIMED). J. Geophys. Res. Atmos., 114(D13), D13107. https://doi.org/10.1029/2008JD011298

Zhang, X. L., Forbes, J. M., Hagan, M. E., Russell III, J. M., Palo, S. E., Mertens, C. J., and Mlynczak, M. G. (2006). Monthly tidal temperatures 20-120 km from TIMED/SABER. J. Geophys. Res. Space Phys., 111(A10), A10S08. https://doi.org/10.1029/2005JA011504 